\title{
Introducing the Bird Chromosome Database: An Overview of Cytogenetic Studies in Birds
}

\author{
Tiago M. Degrandi ${ }^{a}$ Suziane A. Barcellos ${ }^{b}$ Alice L. Costa ${ }^{b}$ Analía D.V. Garnero ${ }^{b}$ \\ Iris Hass ${ }^{\text {a }}$ Ricardo J. Gunski ${ }^{\text {b }}$ \\ a Department of Genetics, Universidade Federal do Paraná (UFPR), Curitiba, Brazil; b Universidade Federal do Pampa \\ (UNIPAMPA), Campus São Gabriel, São Gabriel, Brazil
}

\section{Keywords}

Chicken · Comparative map · Database · Diploid number ·

Evolution · Karyotypes

\section{Abstract}

Bird chromosomes, which have been investigated scientifically for more than a century, present a number of unique features. In general, bird karyotypes have a high diploid number (2n) of typically around 80 chromosomes that are divided into macro- and microchromosomes. In recent decades, FISH studies using whole chromosome painting probes have shown that the macrochromosomes evolved through both inter- and intrachromosomal rearrangements. However, chromosome painting data are available for only a few bird species, which hinders a more systematic approach to the understanding of the evolutionary history of the enigmatic bird karyotype. Thus, we decided to create an innovative database through compilation of the cytogenetic data available for birds, including chromosome numbers and the results of chromosome painting with chicken (Gallus gallus) probes. The data were obtained through an extensive literature review, which focused on cytogenetic studies published up to 2019. In the first version of the "Bird Chromosome Database (BCD)" (https://sites.unipampa.edu.br/birdchromosomedatabase) we have compiled data on the chromosome numbers of 1,067 bird species and chromosome painting data on 96 species. We found considerable variation in the diploid numbers, which ranged from 40 to 142 , although most (around 50\%) of the species studied up to now have between 78 and 82 chromosomes. Despite its importance for cytogenetic research, chromosome painting has been applied to less than $1 \%$ of all bird species. The BCD will enable researchers to identify the main knowledge gaps in bird cytogenetics, including the most under-sampled groups, and make inferences on chromosomal homologies in phylogenetic studies.

(c) 2020 S. Karger AG, Basel

Databases present a valuable source of information for research on a wide range of topics, including species inventories, cytogenetics of some key groups, chromosomal mapping of rDNA, and even complete genomic sequences [Peruzzi and Bedini, 2014; Jarvis et al., 2015; Cardoso et al., 2018; Gill and Donsker, 2018; Paresque et al., karger@karger.com www.karger.com/cgr

(c) 2020 S. Karger AG, Base

Karger'
Tiago M. Degrandi

Department of Genetics, Universidade Federal do Paraná

Avenida Coronel Francisco H. dos Santos, 100

Curitiba, PR 81530-000 (Brazil)

t.degrandi@yahoo.com.br 
2018; Sochorová et al., 2018; Perkins et al., 2019]. They also provide researchers with an overview of these studies, helping to identify gaps and the need for the application of new and complementary approaches.

The class Aves is an important and extremely diverse biological group that includes more than 10,000 species [Gill and Donsker, 2018]. Over the past decade, considerable efforts have been made to reconstruct the evolutionary history of this group, and one of the most important advances has come from the sequencing of the entire genomes of 48 species [Jarvis et al., 2015]. This genomic analysis permitted the review of the evolutionary relationships among the different avian orders and supports an initial divergence of the birds into 2 groups, Paleognathae and Neognathae [Jarvis et al., 2014; Prum et al., 2015]. Despite these advances, genomic data are only available for a very small proportion of the total number of bird species [Kretschmer et al., 2018]. Thus, it is important to encourage the application of alternative approaches, such as cytogenetics.

Avian chromosomes have been investigated scientifically for more than a century and have unique characteristics [Guyer, 1900]. Bird karyotypes are composed of 2 groups of chromosomes that differ notably in size: macro- and microchromosomes [Ellegren, 2010]. In general, macrochromosomes are $2.5-6 \mu \mathrm{m}$ in length and comprise the first 10 chromosome pairs, whereas microchromosomes are more numerous and less than $2.5 \mu \mathrm{m}$ long [Rodionov, 1996]. The diploid number $(2 \mathrm{n})$ is high in most species, i.e., around 80 chromosomes [Griffin et al., 2007]. Concerning the sex chromosome system, females are heterogametic (ZW) and males are homogametic (ZZ) [Graves and Shetty, 2001; Wang et al., 2014].

FISH studies using whole chromosome painting probes (WCPs) have permitted the identification of many chromosomal rearrangements in the avian karyotype [Kretschmer et al., 2018]. The domestic fowl, Gallus gallus (GGA), $2 \mathrm{n}=78$, was the first bird species from which WCPs were isolated [Griffin et al., 1999]. These GGA probes have been used successfully to determine the chromosomal homologies between distantly related species such as ostrich (Struthio camelus), American rhea (Rhea americana), canary (Serinus canaria), and zebra finch (Taeniopygia guttata) [Nishida-Umehara et al., 2007; dos Santos et al., 2017]. For example, chromosome painting with GGA probes in eagles (Accipitridae) has shown that the macrochromosomes of these birds evolved through interchromosomal rearrangements such as fusions, fissions, and chromosome transloca- tions, leading to a decrease in the diploid number to 5868 [de Oliveira et al., 2005]. Species-specific probes have also been developed for other species, such as Burhinus oedicnemus (Charadriiformes), Leucopternis albicollis and Gyps fulvus (Accipitriformes), and Zenaida auriculata (Columbiformes) [Nie et al., 2009, 2015; de Oliveira et al., 2010; Kretschmer et al., 2018b]. The WCPs of $L$. albicollis have proven especially important for the detection of intrachromosomal rearrangements that are not detected by GGA probes [dos Santos et al., 2015; Degrandi et al., 2017].

Considering the importance of the cytogenetic data for the understanding of bird evolution, the present study compiled the cytogenetic data available on birds to create a database that covers the chromosome numbers and chromosome painting data reported for the different bird species to date (up to 2019). Access to these data will permit researchers to identify the priority groups for new studies, patterns of chromosomal homology, and the processes involved in the evolution of karyotype structure, and will provide important insights into the phylogeny of these vertebrates.

\section{Materials and Methods}

In the present study, we compiled the data available for chromosome numbers in bird species and chromosome painting with GGA probes, published up to 2019. These data were used to create the "Bird Chromosome Database."

Initially, we examined the data presented in review studies, such as those of Bloom [1969], Ray-Chaudhuri [1973], Shields [1982], de Boer [1984], Capanna et al. [1987], Santos and Gunski [2006], Griffin et al. [2007], Cuervo et al. [2011], and Kretschmer et al. [2018a], verifying each paper cited by these authors. We also conducted literature searches in the Web of Science and Google Scholar databases to identify complementary material, using the keywords "birds," "2n," "chromosome number," "karyotype description," "whole chromosome painting," "GGA probes," and "FISH." We compiled a total of 300 studies, which included congress abstracts, theses, dissertations, and research papers. These studies were allocated to one of 2 categories, according to the type of data presented: (1) studies with data on chromosome numbers and karyotype descriptions, and (2) studies that provide data on chromosome painting with G. gallus probes.

The data were arranged in a table that includes a list of species and the complete reference for each study. The scientific name of each species was checked against the World Bird List v8.2 of the International Community of Ornithologists [Gill and Donsker, 2018], and any synonyms were placed in a separate column to facilitate access by the user. Finally, for an overview of the cytogenetic data currently available in the database, we ran basic statistical analyses, including the percentage of bird species that have been karyotyped and frequency and variation in the diploid numbers, using Libreoffice tools. 


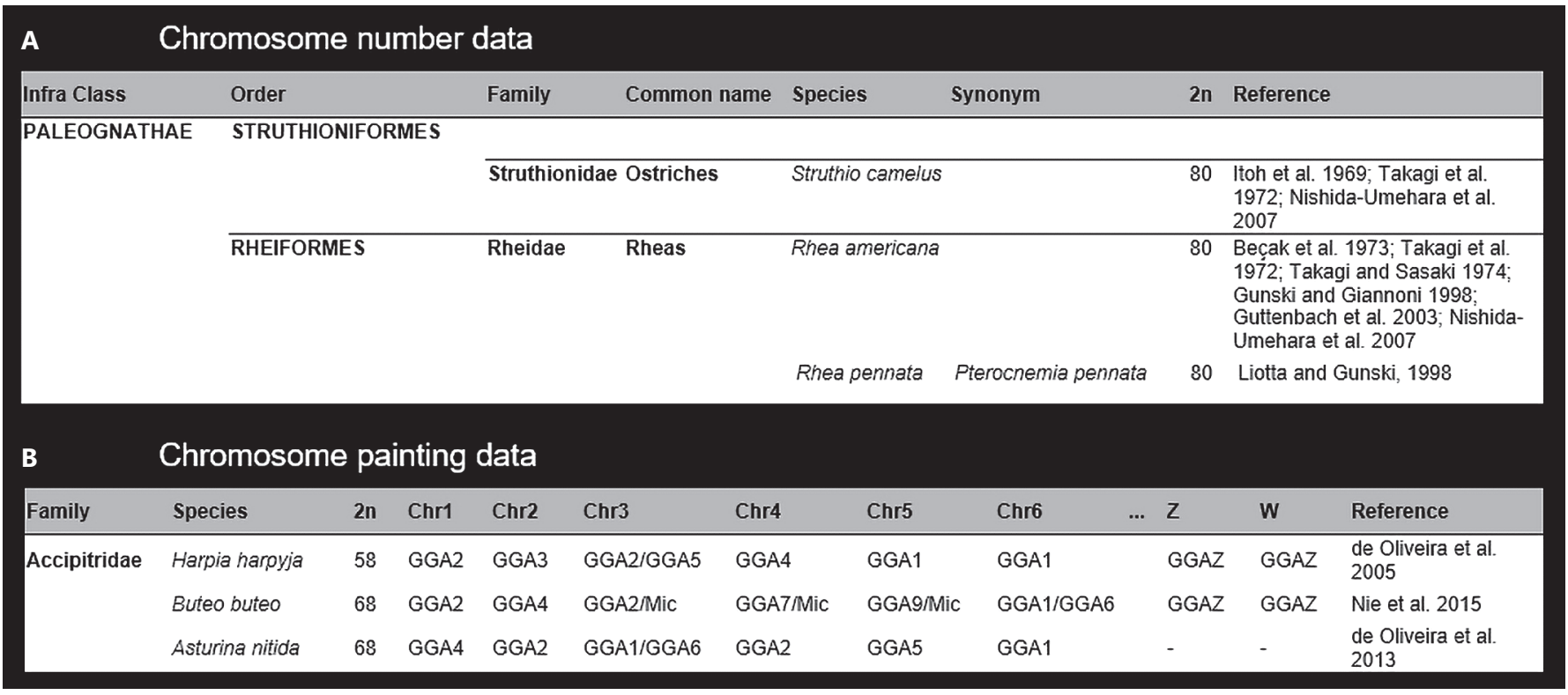

Fig. 1. Examples of cytogenetic data readouts from the Bird Chromosome Database. A Chromosome number (2n) data for the orders Struthioniformes and Rheiformes. B Homologies between the chromosome pairs (Chr1, ...) of 3 accipitrids and G. gallus. When 2 or more GGA chromosomes are associated with the target chromosome, they are presented as first/second, as in the case of Chr3 of Harpia harpyja, which shows homologies with GGA2/GGA5. Both tables present the current zoological classification of each species and the references from which the data were obtained.

\section{Results and Discussion}

Given the historical advances in birds cytogenetics, a number of review studies and compilations of the species with known chromosome numbers have been published over the years, including the reports of Bloom [1969], Ray-Chaudhuri [1973], Shields [1982], de Boer [1984], Capanna et al. [1987], Christidis [1990], Santos and Gunski [2006], and Cuervo et al. [2011]. In addition, other important studies compare chromosome painting data, e.g., Griffin et al. [2007] and Kretschmer et al. [2018a]. These studies provided an overview of the diversity of bird karyotypes and the principal mechanisms through which karyotypes evolve. To facilitate access to the available cytogenetic data, we created the Bird Chromosome Database (BCD) available at https://sites.unipampa.edu. br/birdchromosomedatabase. This database provides an important new source of information for researchers, allowing them to identify priority groups for future studies.

In its first version, the BCD includes 2 datasets: the first contains a list of 1,067 species with known chromosome numbers, and the second comprises chromosome painting data for 96 species, analyzed with the G. gallus
WCPs. To access these data, the user has to download the files in ODS format by using one of the tabs "Chromosome Number Data" or "Chromosome Painting Data." Examples of the results of this procedure are shown in Figure 1.

The analysis of the data available in the BCD indicates that karyotypes have been described for $9.83 \%$ of the total number of bird species found worldwide [Gill and Donsker, 2018], representing 37 of the 40 current orders and 138 of the 248 families. The most complete study of this type was that of Christidis [1990], which includes the karyotypes of 800 species.

In some orders, i.e., the Rheiformes, Eurypygiformes, Cariamiformes, and Opisthocomiformes, karyotypes are available for all (100\%) species (Table 1), followed by the Ciconiiformes with $73.68 \%$ of species karyotyped, and the Struthioniformes, Casuariiformes, and Phoenicopteriformes, with $50 \%$ of the species karyotyped. Other orders, such as the Accipitriformes (26\% of species karyotyped), Falconiformes (21\%), Psittaciformes (21\%), and Passeriformes (7\%), are less well represented, although they include large numbers of species. By contrast, no records on the karyotypes of the orders Phaethontiformes, Mesitor- 
nithiformes, and Leptosomiformes were identified, which highlights these taxa as important targets for future research.

Considering all the bird species karyotyped to date, we found an extraordinary diversity in the number of chromosomes (Fig. 2), ranging from $2 \mathrm{n}=40$ in Falco columbarius (Falconiformes) to 142 in Corythaixoides concolor (Musophagiformes). Similar variation has been observed in other groups, such as in amphibians, where diploid numbers range from $2 \mathrm{n}=14$ to $2 \mathrm{n}=108$ [Perkins et al., 2019], or in ants (Formicidae), in which haploid numbers (n) range from $n=1$ to $n=60$ [Cardoso et al., 2018]. Despite the ample variation found here, most birds $(50.7 \%$ of the BCD records) have diploid numbers between 78 and 82 , and $21.7 \%$ have $2 n=80$ (Fig. 2). Griffin et al. [2007] proposed a putative ancestral bird karyotype of $2 n=80$, which has provided an excellent model for the comparative analysis of the degree of conservation of bird karyotypes.

We also analyzed the variation in the chromosome numbers among orders (Fig. 3), with considerable variation being found among species in some orders. In the Coraciiformes, diploid numbers range from 40 to 132 and from 68 to 126 in the Bucerotiformes. In the Charadriiformes 42-94 chromosomes were observed, 62-114 in the Piciformes, 40-92 in the Falconiformes, and 46-92 in the Psittaciformes. Negligible variation was found in some other orders, however. In the Tinamiformes, the diploid numbers of the 6 known karyotypes ranged from 78 to 80 (Fig. 3).

Comparative chromosome painting is especially important for the understanding of the processes determining the variation in chromosome number and karyotype structure. The karyotype of G. gallus is an excellent model for this comparison, permitting the identification of chromosome homologies between birds of different orders, including those from the Paleognathae and Neognathae clades [de Oliveira et al., 2005; Nishida-Umehara et al., 2007; dos Santos et al., 2017]. The BCD dataset includes the chromosomal homologies of 96 bird species, representing 36 families and 18 orders (Table 1), and corresponding to less than $1 \%$ of all avian diversity. The orders with the most species analyzed are Falconiformes, Accipitriformes, Galliformes, and Passeriformes (Table 1). In a recent review, Kretschmer et al. [2018a] identified the chromosomal rearrangements occurring in the bird evolution, such as the chromosome fission of GGA1 in all Passeriformes species and the fusion of GGA6 +7 and GGA8 + 9 in Psittaciformes. Similar results would be expected in other groups, such as the Piciformes and Coraciiformes, which have yet to be analyzed by WCP, but present considerable interspecific variation in chromosome numbers.
Table 1. Total number of bird species per order and numbers and percentages of species karyotyped and analyzed with chicken painting probes

\begin{tabular}{|c|c|c|c|c|c|}
\hline \multirow[t]{2}{*}{ Order } & \multirow{2}{*}{$\begin{array}{l}\text { Total } \\
\text { number of } \\
\text { species }^{\mathrm{a}}, N\end{array}$} & \multicolumn{2}{|c|}{$\begin{array}{l}\text { Species } \\
\text { karyotyped }\end{array}$} & \multicolumn{2}{|c|}{$\begin{array}{l}\text { Species studied by } \\
\text { chicken WCPs }\end{array}$} \\
\hline & & $n$ & $\%$ & $n$ & $\%$ \\
\hline Struthioniformes & 2 & 1 & 50.00 & 1 & 50.00 \\
\hline Rheiformes & 2 & 2 & 100.00 & 2 & 100.00 \\
\hline Apterygiformes & 5 & 1 & 20.00 & - & - \\
\hline Casuariiformes & 4 & 2 & 50.00 & 2 & 50.00 \\
\hline Tinamiformes & 47 & 6 & 12.77 & 1 & 2.13 \\
\hline Anseriformes & 177 & 46 & 25.99 & 8 & 4.52 \\
\hline Galliformes & 300 & 54 & 18.00 & 16 & 5.33 \\
\hline Gaviiformes & 5 & 1 & 20.00 & - & - \\
\hline Sphenisciformes & 18 & 8 & 44.44 & - & - \\
\hline Eurypygiformes & 2 & 2 & 100.00 & 1 & 50.00 \\
\hline Procellariiformes & 147 & 5 & 3.40 & - & - \\
\hline Podicipediformes & 23 & 4 & 17.39 & - & - \\
\hline Phoenicopteriformes & 6 & 3 & 50.00 & - & - \\
\hline Phaethontiformes & 3 & - & - & - & - \\
\hline Ciconiiformes & 19 & 14 & 73.68 & 2 & 10.53 \\
\hline Pelecaniformes & 118 & 35 & 29.66 & - & - \\
\hline Suliformes & 61 & 5 & 8.20 & - & - \\
\hline Accipitriformes & 266 & 68 & 25.56 & 11 & 4.14 \\
\hline Otidiformes & 26 & 1 & 3.85 & - & - \\
\hline Mesitornithiformes & 3 & - & - & - & - \\
\hline Cariamiformes & 2 & 2 & 100.00 & - & - \\
\hline Gruiformes & 189 & 30 & 15.87 & 2 & 1.06 \\
\hline Charadriiformes & 383 & 64 & 16.71 & 3 & 0.78 \\
\hline Pterocliformes & 16 & 1 & 6.25 & - & - \\
\hline Opisthocomiformes & 1 & 1 & 100.00 & 1 & 100.00 \\
\hline Columbiformes & 344 & 32 & 9.30 & 5 & 1.45 \\
\hline Musophagiformes & 23 & 3 & 13.04 & - & - \\
\hline Cuculiformes & 149 & 12 & 8.05 & - & - \\
\hline Strigiformes & 243 & 32 & 13.17 & 3 & 1.23 \\
\hline Caprimulgiformes & 122 & 10 & 8.20 & - & - \\
\hline Apodiformes & 481 & 11 & 2.29 & - & - \\
\hline Coliiformes & 6 & 1 & 16.67 & - & - \\
\hline Trogoniformes & 43 & 2 & 4.65 & 1 & 2.33 \\
\hline Leptosomiformes & 1 & - & - & - & - \\
\hline Coraciiformes & 177 & 13 & 7.34 & - & - \\
\hline Bucerotiformes & 74 & 6 & 8.11 & - & - \\
\hline Piciformes & 445 & 32 & 7.19 & - & - \\
\hline Falconiformes & 67 & 14 & 20.90 & 6 & 8.96 \\
\hline Psittaciformes & 398 & 83 & 20.85 & 9 & 2.26 \\
\hline Passeriformes & 6,459 & 460 & 7.12 & 22 & 0.34 \\
\hline Total entries & 10,857 & 1,067 & 9.83 & 96 & 0.88 \\
\hline
\end{tabular}




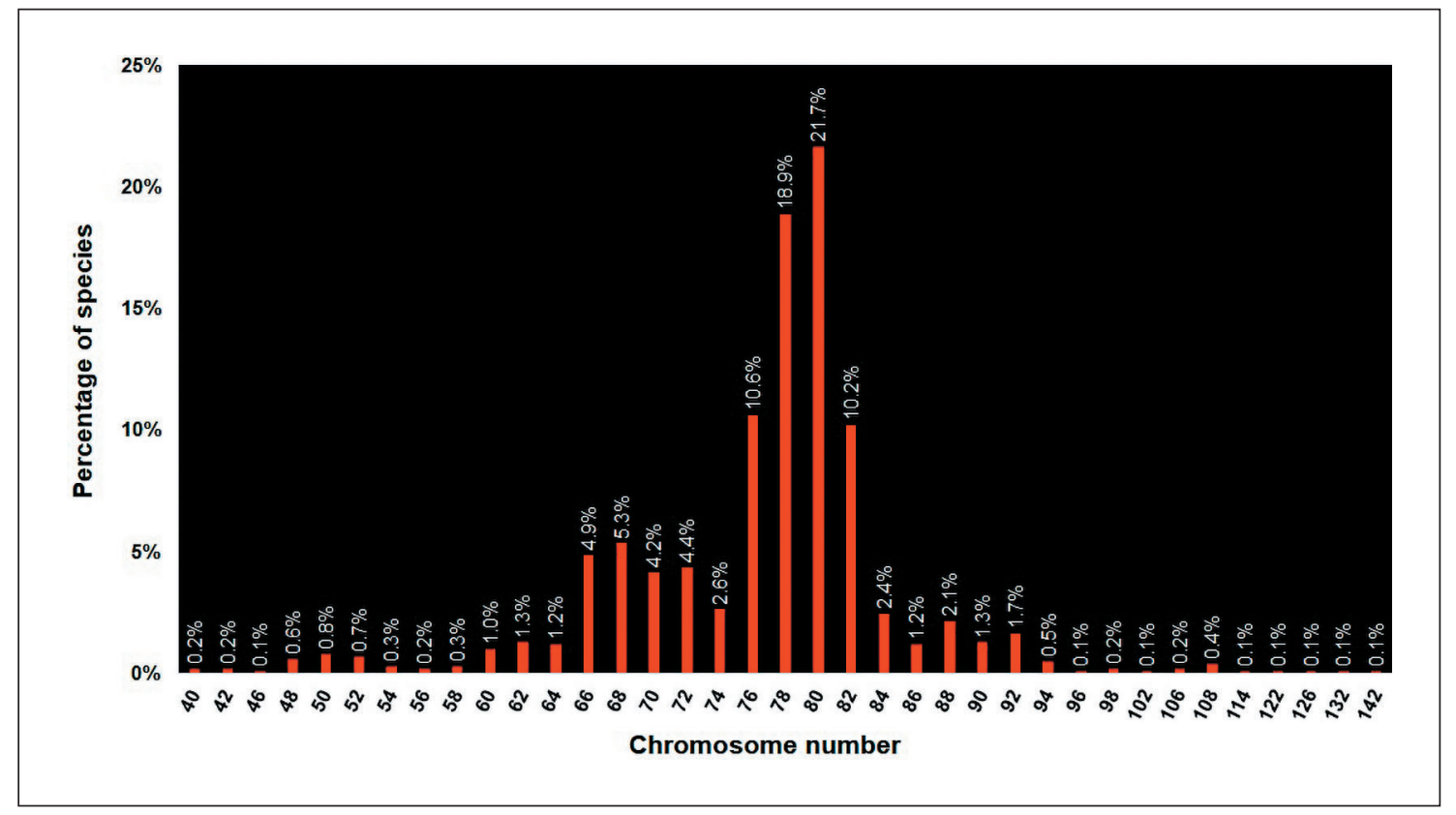

Fig. 2. Frequencies of the different diploid chromosome numbers found in birds.

Fig. 3. Range of variation in diploid chromosome numbers in different bird orders. In $50 \%$ of the species, $2 \mathrm{n}$ ranges from 78 (blue dotted line) to 82 (yellow dotted line). This figure is modified from the review of Shields [1982].

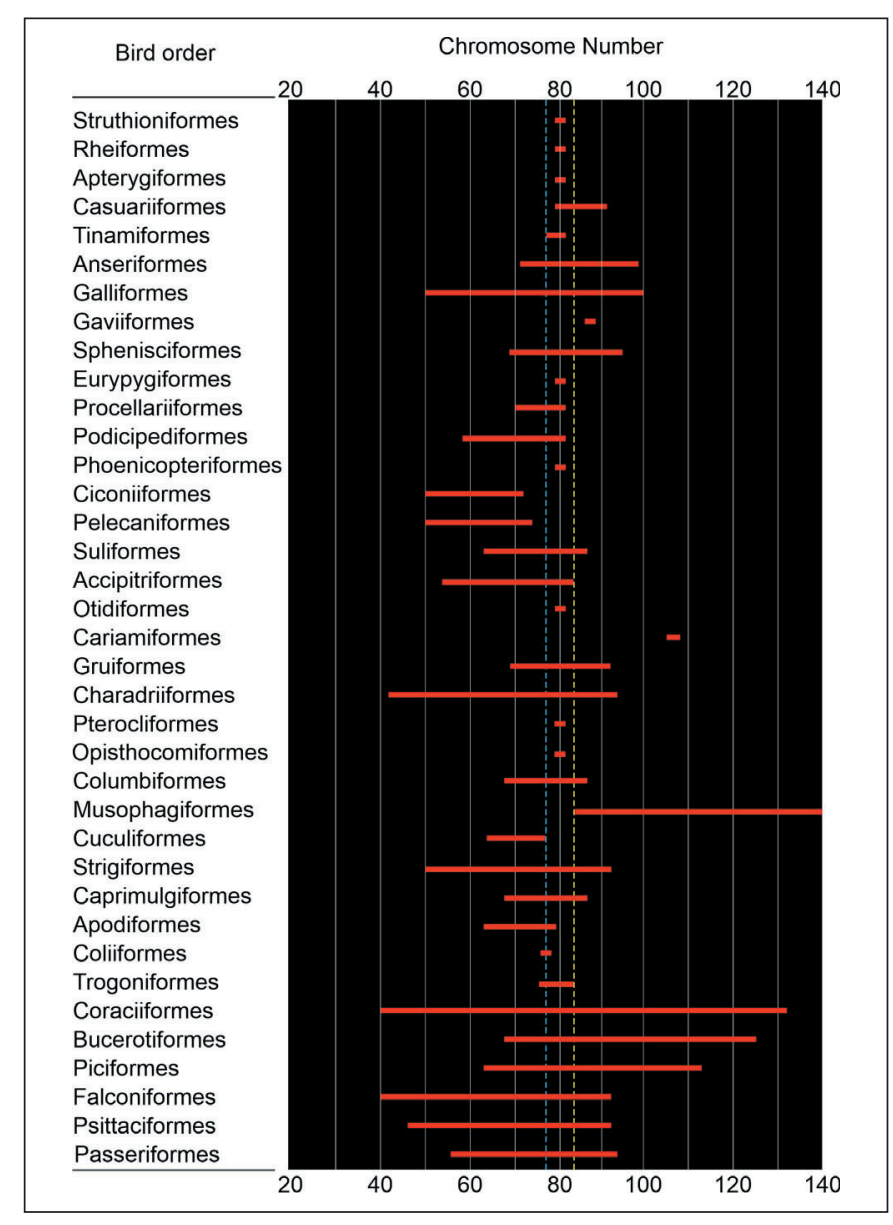

Cytogenet Genome Res 2020;160:199-205 DOI: $10.1159 / 000507768$ 


\section{Conclusion}

Although a large number of bird species have been karyotyped, only a few or no cytogenetic data whatsoever are available for the vast majority of species. The scenario is even bleaker in the case of the chromosome painting data, which are available for less than $1 \%$ of all known bird diversity. Given this, we hope that our database will help researchers to identify knowledge gaps in the cytogenetics of birds and the priority groups for research, and call forth feedback for the improvement of the dataset and the website. The species list and cytogenetic data will be updated at the beginning of each year and any contributions or suggestions are encouraged. They can be sent to birdschromosome@gmail.com.

\section{Acknowledgements}

We thank the Universidade Federal do Pampa (UNIPAMPA) for technical support for the development of the website.

\section{Statement of Ethics}

The authors have no ethical conflicts to disclose.

\section{Disclosure Statement}

The authors have no conflicts of interest to declare.

\section{Funding Sources}

T.M.D. received a scholarship (Finance Code 001) from Coordenação de Aperfeiçoamento de Pessoal de Nível Superior - Brasil (CAPES).

\section{Author Contributions}

The project was delineated by T.M.D. and supervised by R.J.G. Data were acquired by T.M.D., S.A.B., and A.L.C. T.M.D., A.D.V.G., I.H., and R.J.G. ran data analyses. T.M.D., S.A.B., and A.L.C. participated in the writing of the manuscript. All authors read and approved the final version of the manuscript.

\section{References}

Bloom SE: A current list of chromosome numbers and variations for species of the avian subclass Carinatae. J Hered 60:217-220 (1969).

Capanna E, Civitelli M, Martinico EI: I cromosomi degli uccelli. Citotassonomia ed evoluzione cariotipica. Avocetta 11:101-143 (1987)

-Cardoso DC, Santos HG, Cristiano MP: The Ant Chromosome database - ACdb: an online resource for ant (Hymenoptera: Formicidae) chromosome researchers. Myrmecol News 27:87-91 (2018)

Christidis L: Animal Cytogenetics, Chordata 3: B Aves (Gebrüder Borntraeger, Berlin 1990).

Cuervo P, Quero M, Gorla N: Conocimiento citogenetico de las aves de Argentina. Ornitol Neotrop 22:517-537 (2011).

de Boer LEM: New developments in vertebrate cytotaxonomy VIII. A current list of references on avian karyology. Genetica 65:3-6 (1984).

Degrandi TM, Garnero ADV, O'Brien PCM, Ferguson-Smith MA, Kretschmer R, et al: Chromosome painting in Trogon s. surrucura (Aves, Trogoniformes) reveals a karyotype derived by chromosomal fissions, fusions, and inversions. Cytogenet Genome Res 151: 208-215 (2017).

de Oliveira EHC, Habermann FA, Lacerda O, Sbalqueiro IJ, Wienberg J, Müller S: Chromosome reshuffling in birds of prey: the karyotype of the world's largest eagle (Harpy eagle, Harpia harpyja) compared to that of the chicken (Gallus gallus). Chromosoma 114: 338-343 (2005). de Oliveira EHC, Tagliarini MM, Rissino JD, Pieczarka JC, Nagamachi CY, et al: Reciprocal chromosome painting between white hawk (Leucopternis albicollis) and chicken reveals extensive fusions and fissions during karyotype evolution of Accipitridae (Aves, Falconiformes). Chromosome Res 18:349-355 (2010).

dos Santos MDS, Kretschmer R, Silva FAO, Ledesma MA, O'Brien PC, et al: Intrachromosomal rearrangements in two representatives of the genus Saltator (Thraupidae, Passeriformes) and the occurrence of heteromorphic $\mathrm{Z}$ chromosomes. Genetica 143:535-543 (2015).

dos Santos MDS, Kretschmer R, Frankl-Vilches C, Bakker A, Gahr M, et al: Comparative cytogenetics between two important songbird, models: the zebra finch and the canary. PLoS One 12:e0170997 (2017).

-Ellegren H: Evolutionary stasis: the stable chromosomes of birds. Trends Ecol Evol 25:283291 (2010).

Gill F, Donsker D: IOC World Bird List v.8.2. Available from https://doi.org/10.14344/ IOC.ML.8.1 (2018).

Graves JAM, Shetty S: Sex from W to Z: evolution of vertebrate sex chromosomes and sex determining genes. J Exp Zool 290:449-462 (2001).

Griffin DK, Haberman F, Masabanda J, O’Brien PMC, Bagga M, et al: Micro- and macrochromosome paints generated by flow cytometry and microdissection: tools for mapping the chicken genome. Cytogenet Genome Res 87: 278-281 (1999).
Griffin DK, Robertson LBW, Tempest HG, Skinner BM: The evolution of the avian genome as revealed by comparative molecular cytogenetics. Cytogenet Genome Res 117:64-77 (2007).

Guyer MF: Spermatogenesis of normal and hybrid pigeons. Dissertation, University of Chicago (1900).

- Jarvis ED, Mirarab S, Aberer AJ, Li B, Houde P, et al: Whole-genome analyses resolve early branches in the tree of life of modern birds. Science 346:1320-1331 (2014).

- Jarvis ED, Mirarab S, Aberer AJ, Li B, Houde P, et al: Phylogenomic analyses data of the avian phylogenomics project. Gigascience 4:4 (2015).

Kretschmer R, Ferguson-Smith MA, de Oliveira EHC: Karyotype evolution in birds: from conventional staining to chromosome painting. Genes 9:E181 (2018a).

-Kretschmer R, Furo IDO, Gunski RJ, Garnero ADV, Pereira JC, et al: Comparative chromosome painting in Columbidae (Columbiformes) reinforces divergence in Passerea and Columbea. Chromosome Res 26:211-223 (2018b).

Nie W, O’Brien PCM, Ng BL, Fu B, Volobouev V, et al: Avian comparative genomics: reciprocal chromosome painting between domestic chicken (Gallus gallus) and the stone curlew (Burhinus oedicnemus, Charadriiformes) - an atypical species with low diploid number. Chromosome Res 17:99-113 (2009). 
Nie W, O'Brien PC, Fu B, Wang J, Su W, et al: Multidirectional chromosome painting substantiates the occurrence of extensive genomic reshuffling within Accipitriformes. BMC Evol Biol 15:205 (2015).

Nishida-Umehara C, Tsuda Y, Ishijima J, Ando J, Fujiwara A, et al: The molecular basis of chromosome orthologies and sex chromosomal differentiation in palaeognathous birds. Chromosome Res 15:721-734 (2007).

- Paresque R, Rodrigues JS, Riguetti KB: Karyotypes of Brazilian non-volant small mammals (Didelphidae and Rodentia): an online tool for accessing the chromosomal diversity. Genet Mol Biol 41:605-610 (2018).

-Perkins RD, Gamboa JR, Jonika MM, Lo J, Shum A, et al: A database of amphibian karyotypes. Chromosome Res 27:313-319 (2019).
Peruzzi L, Bedini G: Online resources for chromosome number databases. Caryologia 67: 292-295 (2014).

Prum RO, Berv JS, Dornburg A, Field DJ, Townsend JP, et al: A comprehensive phylogeny of birds (Aves) using targeted next-generation DNA sequencing. Nature 526:569-573 (2015).

Ray-Chaudhuri R: Cytotaxonomy and chromosome evolution in birds, in Chiarelli $\mathrm{AB}, \mathrm{Ca}$ panna E (eds): Cytotaxonomy and Vertebrate Evolution, pp 425-483 (Academic Press, New York 1973).
Rodionov AV: Micro vs. macro: structural-functional organization of avian micro- and macrochromosomes (in Russian). Genetika 32: 597-608 (1996).

Santos LP, Gunski RJ: Revisão de dados citogenéticos sobre a avifauna brasileira. Rev Brasil Ornitol 14:35-45 (2006).

Shields GF: Comparative avian cytogenetics: a review. Condor 84:45-58 (1982).

Sochorová J, Garcia S, Gálvez F, Symonová R, Kovař́k A: Evolutionary trends in animal ribosomal DNA loci. Introduction to a new online database. Chromosoma 127:141-150 (2018).

-Wang Z, Zhang J, Yang W, An N, Zhang P, et al: Temporal genomic evolution of bird sex chromosomes. BMC Evol Biol 14:250 (2014). 